
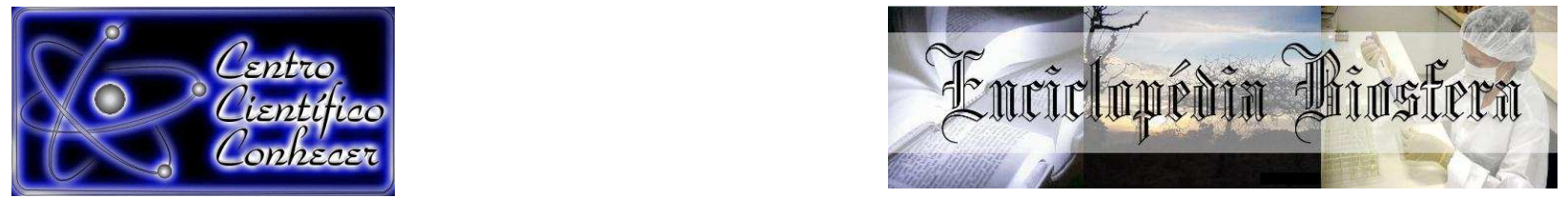

\title{
TRATAMENTO DE EFLUENTE DE INDÚSTRIA DE PAPEL COM AGENTE COAGULANTE TANINO VEGETAL
}

Ana Paula Bacchiega Prestes ${ }^{1}$; Ana Flavia Bender ${ }^{2}$; Carlos Magno de Souza Vidal ${ }^{3}$; Ludmila Carvalho Neves ${ }^{4}$; Mirelly Manica ${ }^{5}$;

${ }^{1}$ Mestranda, Pós Graduação em Ciências Florestais, Universidade Estadual do Centro-Oeste (aninhabacch@gmail.com), Irati, Paraná-Brasil;

${ }^{2}$ Mestranda, Pós Graduação em Ciências Florestais, Universidade Estadual do Centro-Oeste, Irati, Paraná-Brasil;

${ }^{3}$ Professor Dr., Departamento de Engenharia Ambiental, Universidade Estadual do Centro-Oeste, Irati, Paraná-Brasil;

${ }^{4}$ Doutoranda, Pós Graduação em Ciências Florestais, Universidade Estadual do Centro-Oeste, Irati, Paraná-Brasil;

${ }^{5}$ Graduanda, Graduação Engenharia Ambiental, Universidade Estadual do CentroOeste, Irati, Paraná-Brasil.

\section{Recebido em: 03/10/2016 - Aprovado em: 21/11/2016 - Publicado em: 05/12/2016 DOI: 10.18677/EnciBio_2016B_098}

\begin{abstract}
RESUMO
As indústrias de celulose e papel apresentam grande consumo de recursos naturais, estando entre as que mais produzem efluentes no setor industrial. Devido a esta problemática,várias tecnologias estão sendo utilizadas para o tratamento deste efluente. Portanto, propõe-se neste trabalho a utilização do coagulante natural Tanino no tratamento do efluente de uma indústria de papel, através do processo de coagulação/floculação/decantação, com a finalidade de se verificar sua eficiência de remoção dos parâmetros: turbidez, cor aparente, cor verdadeira, demanda química de oxigênio (DQO), sólidos totais e sólidos suspensos. No processo de tratamento foram utilizadas dosagens de 100, 125, 150, 175 e 200 mg. - $^{-1}$ de tanino.Os parâmetros operacionais adotados no jar-test foram: gradiente de mistura rápida de $550 \mathrm{~s}^{-1}$ e tempo de mistura rápida de 10 segundos para coagulação; gradiente de mistura lenta de $40 \mathrm{~s}^{-1}$ e tempo de mistura lenta de 15 minutos para floculação e velocidade de sedimentação de $0,4 \mathrm{~cm} \cdot \mathrm{min}^{-1}$. Através dos testes estatísticos realizados (regressão linear, ANOVA e teste de Tukey) identificou-se a melhor dosagem que foi de $125 \mathrm{mg} \cdot \mathrm{L}^{-1}$. Sendo assim, utilizando-se da dosagem ótima obteve-se remoção de $88 \%, 83 \%, 60 \%$ e $46 \%$ para turbidez, cor aparente, cor verdadeira e DQO respectivamente. Observou-se no estudo que o tratamento foi eficiente quando empregado como alternativa de pré tratamento, uma vez que o mesmo não alcançou valores elevados de remoção de matéria orgânica.
\end{abstract}

PALAVRAS-CHAVE: Coagulante natural. Ensaios de coagulação. Efluentepapeleiro. 


\title{
TREATMENT OF PAPER INDUSTRY WASTEWATER USING TANNIN-BASED AS A COAGULANT AGENT
}

\begin{abstract}
Pulp and paper industries have large consumption of natural resources and it is among the largest waste producers in the industrial sector. In this way various technologies have been utilized to treat this kind of effluent. Therefore, in this paper it is proposed the use of tannin-based coagulant to treat the effluent from a paper industry through the process of coagulation / flocculation / decantation, in order to verify its removal efficiency for the following parameters: turbidity, apparent color , true color, chemical oxygen demand (COD), total solids and suspended solids. For the coagulation process it was tested the following tannin dosages: $100,125,150$, 175 and $200 \mathrm{mg}^{-1}$. The operating conditions used in the tests were: coagulation velocity gradient of $550 \mathrm{~s}^{-1}$ and rapid mixing time equal to 10 seconds; flocculation velocity gradient of $40 \mathrm{~s}^{-1}$ and slow mixing time equal to 15 minutes; and settling velocity of $0.4 \mathrm{~cm} \cdot \mathrm{min}^{-1}$. Statistical tests (linear regression, ANOVA and Tukey test) identified that the best dosage was $125 \mathrm{mg} \cdot \mathrm{L}^{-1}$. Thereby, using the optimum dosage it was reached $88 \%, 83 \%, 60 \%$ and $46 \%$ of removal for turbidity, apparent color, true color and COD, respectively. It was noted in the study that the treatment using coagulation with tannin-based coagulant was effective only as an alternative pretreatment, since it does not reach high values of removal of organic matter.
\end{abstract}

KEYWORDS: Natural coagulant; Coagulation assays; Papermaking effluent.

\section{INTRODUÇÃO}

Há algum tempo diferentes regiões do Brasil vêm enfrentando períodos de estiagem, fato que tem alertado aos consumidores de água sobre as limitações desse bem. No país o terceiro maior uso de água, em termos de vazão de retirada, deve-se ao abastecimento industrial, atrás somente da agricultura e da pecuária (MARTIN, 2015).

Tratando-se das fábricas de papel e celulose, grandes volumes de água são utilizados em seus processos, gerando assim grandes volumes de efluentes a ser tratado. Em média, a produção de papel gera em média $20-50 \mathrm{~m}^{3}$ de efluentes por tonelada seca de papel (AMARAL et al., 2013, MARTIN, 2015).

As águas residuárias provenientes das indústrias de papel e celulose possuem elevados teores de matéria orgânica, uma vez que a madeira, matéria prima utilizada, apresenta constituintes orgânicos em sua composição. Além disso, durante a produção incorporam-se diversos reagentes químicos aos processos, os quais conferem características específicas ao efluente (SIMONIČ \& VNUČEC, 2011; SRIDHAR et al., 2011).

Diante disso, a fim de adequar o efluente aos padrões de reutilização, como forma de minimizar o consumo de água e/ou propiciar uma melhor eficiência do tratamento de efluentes, é comum associar aos processos convencionais (biológicos) os processos físico-químicos, tais como: coagulação, floculação, flotação, sedimentação, filtração e oxidação (DI BERNARDO, 1993).

O processo físico-químico se caracteriza pela remoção da fase sólida encontrada no efluente e precipitação destes resíduos por intermédio da incorporação de produtos químicos coagulantes, estes são dispersos por uma mistura rápida que tem como objetivo dissipar o coagulante para otimizar o seu aproveitamento, seguida de uma mistura lenta a fim de que se formem flocos. 
Grande parte das impurezas da água podem ser removidas por meio da aplicação destes produtos (MANCUSO et al., 2003). De maneira geral, os procedimentos citados surgiam como uma alternativa de tecnologias de tratamento devido a vantagens como baixo custo, alta eficiência e simplicidade operacional (SINGH et al., 2016).

Os coagulantes são classificados em duas categorias conforme sua natureza molecular: os químicos e os naturais. Pesquisas têm avaliado a aplicação de coagulantes naturais no tratamento de efluentes em substituição aos sintéticos convencionais. Entre os coagulantes naturais destaca-se o Tanino, um polímero orgânico biodegradável extraído da casca de vegetais por meio de um procedimento de dissolução (PELEGRINO, 2011).

De acordo com MARTINS et al. (2014) a substituição dos sais inorgânicos por coagulantes naturais, como o tanino, vem se tornando uma alternativa de grande potencial para o tratamento de água de para abastecimento e/ou águas residuárias. Isso decorre das diversas vantagens do uso desse tipo de coagulante, como a abundância devido à sua origem renovável, biodegradabilidade, não toxicidade e menor geração de lodo. THAKUR et al. (2014) afirmaram ainda que os coagulantes a base de tanino não deixam sais ou íons na água tratada e, não alteram o pH do meio. Diante de toda a problemática exposta, propõe-se neste trabalho avaliar a utilização do coagulante natural Tanino no tratamento do efluente de uma indústria de papel e celulose.

\section{MATERIAL E MÉTODOS}

O efluente utilizado no presente trabalho foi coletado de uma estação de tratamento de efluentes (ETE) de uma indústria de papel do tipo low weight coat localizada no estado do Paraná. Os experimentos foram realizados no laboratório de saneamento ambiental e qualidade da água no departamento de engenharia ambiental localizado na Universidade Estadual do Centro Oeste do Paraná.

Primeiramente realizou-se a caracterização do efluente coletado para os parâmetros: turbidez (uT), temperatura $\left({ }^{\circ} \mathrm{C}\right)$, cor aparente $(\mathrm{uC})$, cor verdadeira (uC), DQO (mg. $\left.\mathrm{L}^{-1}\right)$, sólidos torais $\left(\mathrm{mg} \cdot \mathrm{L}^{-1}\right)$, e sólidos suspensos totais (mg. $\left.\mathrm{L}^{-1}\right)$.Salienta-se que todas as análises deste trabalho foram realizadas de acordo como Standard Methods for the Examination of Waterand Wastewater (APHA, 2012).

Feito isso, o efluente foi submetido ao tratamento de coagulação, floculação e sedimentação em equipamento do tipo Jar-Test (DI BERNARDO, 2002), que possui seis jarros de acrílico com capacidade de dois litros cada e regulador de rotação das hastes misturadoras.

Para a realização dos ensaios foram fixados os seguintes parâmetros operacionais: gradiente de mistura rápida de $550 \mathrm{~s}^{-1}$ e tempo de mistura rápida de 10 segundos para coagulação; gradiente de mistura lenta de $40 \mathrm{~s}^{-1}$ e tempo de mistura lenta de 15 minutos para floculação e velocidade de sedimentação de $0,4 \mathrm{~cm} \cdot \mathrm{min}^{-1}$.

O coagulante selecionado para os testes de coagulação/floculação/decantação foi o Tanino Acquapol S5T, o qual foi extraído da árvore Acácia Negra, que caracteriza-se por ser um líquido castanho escuro, com densidade de 1,07 a $1,17 \mathrm{~g} / \mathrm{cm}^{3}, \mathrm{pH}$ em média de 2,29 e caráter catiônico. As dosagens utilizadas nos testes de otimização foram de 100, 125, 150, 175 e 200 $\mathrm{mg} . \mathrm{L}^{-1}$, e as variáveis respostas foram a turbidez remanescente e a área espectrofotométrica no comprimento de onde de 200 a $700 \mathrm{~nm}$.

Por fim, após o obtenção da dosagem ótima verificou-se a eficiência do tratamento proposto em função da remoção dos parâmetros turbidez, cor aparente, 
cor verdadeira, demanda química de oxigênio (DQO), sólidos totais, e sólidos suspensos totais.

\section{Tratamento Estatístico dos Dados}

A análise dos dados foi organizada em duas etapas. Na primeira etapa (Etapa I) foi efetuada análise de regressão linear para avaliar a relação entre as dosagens de coagulantes e as variáveis respostas (turbidez e área espectrofotométrica). A segunda etapa (Etapa II) foi destinada à realização da Análise de Variância (ANOVA), seguido de teste de Tukey para identificação da dosagem (dentre as dosagens testadas) mais eficiente para o tratamento. Cabe salientar que previamente os dados foram checados quanto à homogeneidade de variância pelo teste de Bartlett. O nível de significância para todos os testes foi de $5 \%$ de probabilidade de erro. O procedimento dos cálculos foram realizados com o auxílio do software Assistat7.7 beta. Todos os experimentos da pesquisa foram realizados em triplicatas.

\section{RESULTADOS E DISCUSSÃO}

\section{Caracterização do efluente bruto}

Durante a realização dos ensaios os parâmetros temperatura e pH não foram alterados. Notam-se valores elevados de cor verdadeira, DQO e sólidos totais remanescentes ao tratamento empregado na fábrica (Tabela 1).

TABELA 1. Características da amostra do efluente bruto

\begin{tabular}{|c|c|}
\hline Parâmetro & Caracterização \\
\hline $\mathrm{pH}$ & 7,1 \\
\hline Temperatura $\left({ }^{\circ} \mathrm{C}\right)$ & 20 \\
\hline Turbidez (uT) & 88,9 \\
\hline Cor Aparente (uC) & 880 \\
\hline Cor Verdadeira (uC) & 224 \\
\hline $\mathrm{DQO}\left(\mathrm{mg} \cdot \mathrm{L}^{-1}\right)$ & 753 \\
\hline Sólidos Totais (mg.t-1 $)$ & 1.656 \\
\hline Sólidos Suspensos Totais (mg. $\mathrm{L}^{-1}$ ) & 54 \\
\hline
\end{tabular}

Análise de regressão para os dados observados: turbidez remanescente e área espectrofotométrica - ETAPA I

Nas Figuras 1 e 2 são apresentados os resultados dos ajustes realizados para os dados observados de turbidez remanescente e área espectrofotométrica respectivamente, ambos em função das dosagens do coagulante tanino. 


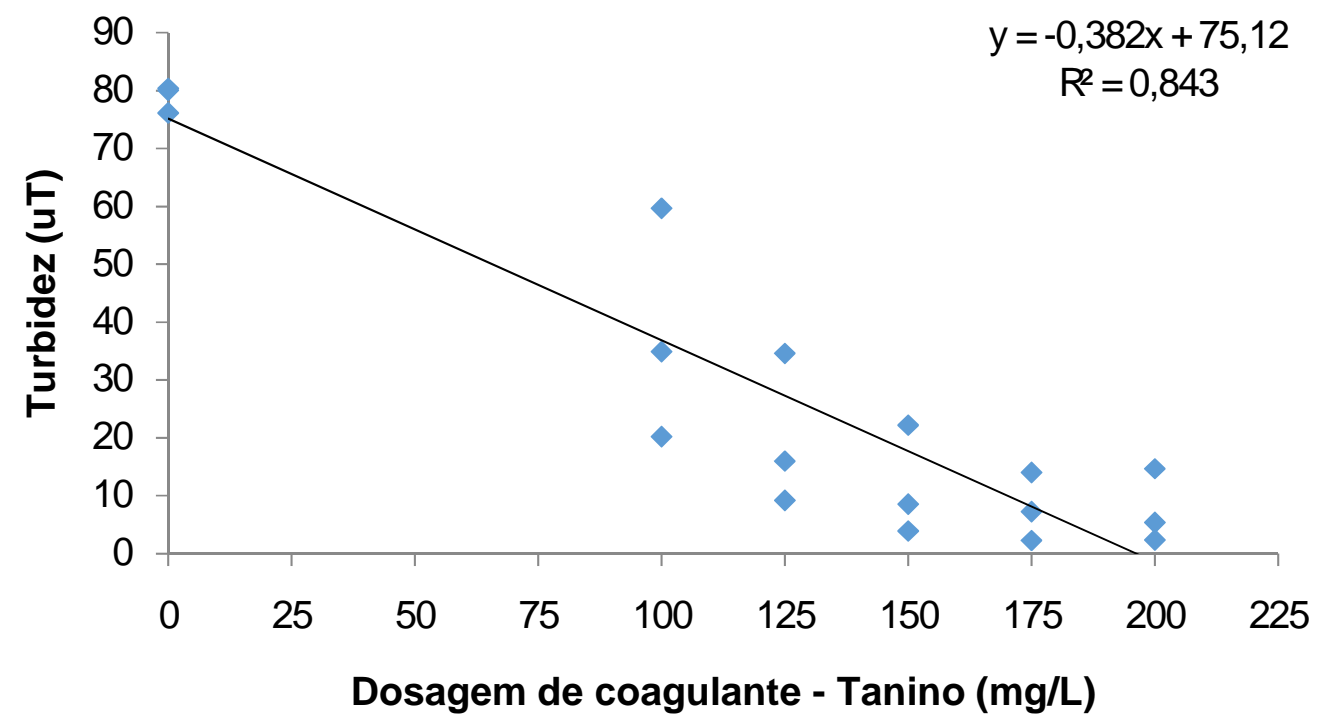

FIGURA 1 - Análise de regressão para os valores de turbidez observados.

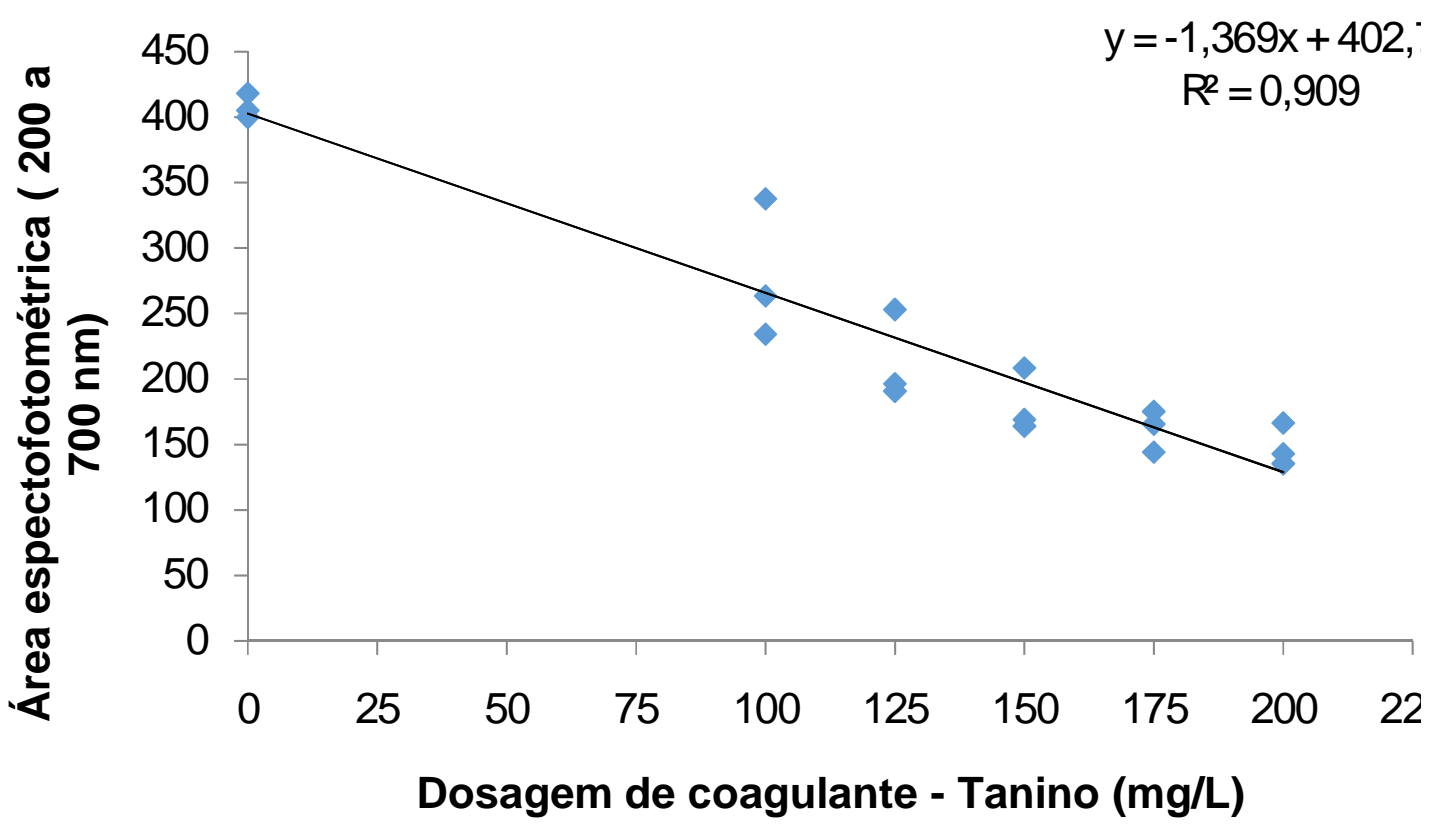

FIGURA 2 - Análise de regressão para os valores da área espectrofotométrica.

Diante dos valores dos coeficientes de determinação $\left(R^{2}\right)$ e das dispersões dos dados apresentados nas Figuras 1 e 2 pode se afirmar que, a dosagem de coagulante influenciou fortemente em ambas variáveis respostas avaliadas. Percebeu-se que as grandezas mensuradas variaram em sentido contrário à variação de dosagem, ou seja, quanto maior a dosagem de coagulante empregada no experimento coagulação/floculação/sedimentação alcançou-se menores valores de turbidez remanescente e menor a área espectrofotométrica nas amostras de efluente tratadas.

Contudo, a fim de verificar se a redução desses parâmetros mediante ao aumento de dosagem de coagulante são realmente significativas prosseguiu-se com a ANOVA e teste de médias. 
ANOVA e teste Tukey para os dados observados: turbidez remanescente e área espectrofotométrica - ETAPA II

Os resultados obtidos na análise de variância (ANOVA),para o parâmetro turbidez remanescente, podem ser observados na Tabela 2.

TABELA 2 - Análise de variância do parâmetro área do espectro, obtido a partir da varredura espectrofotométrica, utilizando-se diferentes dosagens do coagulante tanino.

\begin{tabular}{ccccc}
\hline $\begin{array}{c}\text { Fonte de variação } \\
\text { (FV) }\end{array}$ & $\begin{array}{c}\text { Grau de } \\
\text { liberdade } \\
\text { (GL) }\end{array}$ & $\begin{array}{c}\text { Soma dos } \\
\text { quadrados } \\
\text { (SQ) }\end{array}$ & $\begin{array}{c}\text { Quadrados } \\
\text { médios } \\
\text { (QM) }\end{array}$ & F \\
\hline Dosagem de Tanino & 5 & 144133,62609 & 28826,72522 & $33,0781^{*}$ \\
Resíduo & 12 & 10457,68573 & 871,47381 & - \\
Total & 17 & 154591,31183 & - & - \\
\hline
\end{tabular}

*Significativo pelo teste $F(p \leq 0,05)$. ns = não significativo pelo teste $F(p \geq 0,05)$.

Os resultados obtidos a partir da análise de variância, para o parâmetro área dos espectros, podem ser verificados na Tabela 3.

TABELA 3 - Análise de variância do parâmetro turbidez remanescente, utilizandose diferentes dosagens do coagulante tanino.

\begin{tabular}{ccccc}
\hline $\begin{array}{c}\text { Fonte de variação } \\
\text { (FV) }\end{array}$ & $\begin{array}{c}\text { Grau de } \\
\text { liberdade } \\
\text { (GL) }\end{array}$ & $\begin{array}{c}\text { Soma dos } \\
\text { quadrados } \\
\text { (SQ) }\end{array}$ & $\begin{array}{c}\text { Quadrados } \\
\text { médios } \\
\text { (QM) }\end{array}$ & F \\
\hline Dosagem de Tanino & 5 & 11537,40278 & 2307,48056 & $18,6745^{\star}$ \\
Resíduo & 12 & 1482,75647 & 123,56304 & - \\
Total & 17 & 13020,15925 & - & -
\end{tabular}

*Significativo pelo teste $F(p \leq 0,05) . n s=$ não significativo pelo teste $F(p \geq 0,05)$.

Observa-se, a partir dos resultados da análise de variância (Tabela 2 e 3), que o fator dosagem de coagulante tanino realmente influenciou $(p \leq 0,05)$ tanto nas médias de turbidez remanescente quanto as médias das áreas dos espectros das amostras, corroborando os resultados obtidos pelas analises realizadas na Etapa.

A partir desses resultados prosseguiu-se para o teste de médias Tukey, para a escolha da dosagem ótima de coagulante tanino. Na tabela 4 encontram-se os resultados do teste de médias Tukey para o parâmetro turbidez remanescente e para as médias das áreas dos espectros, das amostras obtidas a partir das diferentes dosagens testadas.

TABELA 4. Teste de médias Tukey do fator dosagem de coagulante tanino, para os parâmetros turbidez remanescente e área dos espectros.

\begin{tabular}{ccccccc}
\hline \multicolumn{7}{c}{ Dosagem $\mathbf{( m g . L ^ { - 1 } )}$} \\
Parâmetros & 0 & 100 & 125 & 150 & 175 & 200 \\
\hline Turbidez & $78.80 \mathrm{a}$ & $38.23 \mathrm{~b}$ & $19.93 \mathrm{bc}$ & $11.54 \mathrm{bc}$ & $7.84 \mathrm{bc}$ & $7.47 \mathrm{c}$ \\
Varredura & $407.76 \mathrm{a}$ & $278.45 \mathrm{~b}$ & $213.36 \mathrm{bc}$ & $180.44 \mathrm{c}$ & $161.60 \mathrm{c}$ & $148.12 \mathrm{C}$ \\
\hline Médias seguidas da mesma letra não & diferem estatisticamente entre si, pelo teste de \\
Tukey a 5\% de probabilidade.
\end{tabular}


Verifica-se na Tabela 4 que ambos os parâmetros estudados demonstraram diferença estatística significativa apenas com o uso das dosagens de 0 e $100 \mathrm{mg} \cdot \mathrm{L}^{-1}$ de coagulante, quando comparadas com as médias obtidas com as demais dosagens de coagulante. Observa-se que ambos os parâmetros apresentaram resultados estatisticamente iguais para as dosagens de $125,150,175$ e $200 \mathrm{mg} \cdot \mathrm{L}^{-1}$ (a partir da dosagem de $125 \mathrm{mg} . \mathrm{L}^{-1}$ tanto as médias de turbidez quanto as médias das áreas estão seguidas da mesma letra). Dessa forma optou-se pela dosagem menor (125 mg. $\left.\mathrm{L}^{-1}\right)$, minimizando a quantidade de coagulante a ser aplicada no tratamento e consequentemente reduzindo-se os custos.

GAVINO (2016) avaliou o uso do coagulante S5T para o processo de coagulação de efluente de indústria de papel e celulose, testando dosagens de 72 a $432 \mathrm{mg} . \mathrm{L}^{-1}$ nos tempos de sedimentação de 5, 10 e 15 minutos,onde a dosagem de $160 \mathrm{mg} \cdot \mathrm{L}^{-1}$ foi adotada como sendo a dosagem ótima, tendo atingido eficiência de remoção acima de $97 \%$ para os parâmetros turbidez e cor do efluente, no tempo de sedimentação de 10 minutos.

Após etapa de otimização realizou-se novamente os ensaios de coagulação, floculação e sedimentação utilizando-se a dosagem ótima de $125 \mathrm{mg} \cdot \mathrm{L}^{-1} . \mathrm{Na}$ Tabela 5 , estão apresentados os resultados obtidos no segundo ensaio, com a dosagem de $125 \mathrm{mg} . \mathrm{L}^{-1} \mathrm{de}$ coagulante tanino, bem como a porcentagem de redução dos parâmetros avaliados após o tratamento.

TABELA 5. Porcentagem de redução dos parâmetros avaliados para o efluente papeleiro.

\begin{tabular}{cccc}
\hline Parâmetro & $\begin{array}{c}\text { Efluente } \\
\text { Bruto }\end{array}$ & $\begin{array}{c}\text { Efluente } \\
\text { Tratado }\end{array}$ & $\begin{array}{c}\text { Porcentagem } \\
\text { de Redução } \\
(\%)\end{array}$ \\
\hline $\mathrm{pH}$ & 7,1 & 7,0 & - \\
Turbidez (uT) & 88,9 & 10,4 & 88 \\
Cor aparente (uC) & 880 & 149,3 & 83 \\
Cor verdadeira(uC) & 224 & 88,6 & 60 \\
DQO $\left(\mathrm{mg} \cdot \mathrm{L}^{-1}\right)$ & 753 & 408 & 46 \\
Sólidos Totais $\left(\mathrm{mg} \cdot \mathrm{L}^{-1}\right)$ & 1.656 & 1.545 & 7 \\
Sólidos Suspensos $\left(\mathrm{mg} \cdot \mathrm{L}^{-1}\right)$ & 54 & 18 & 67 \\
\hline
\end{tabular}

A partir das porcentagens de remoção encontradas na Tabela 5, observa-se que o tratamento empregado proporcionou considerável remoção de turbidez $(88 \%)$ e cor aparente (83\%). Quanto à eficiência de remoção da DQO e cor verdadeira os valores obtidos não foram tão elevados, onde atingiram-se $46 \%$ e $60 \%$ respectivamente.

Ao trabalhar com efluente do mesmo ramo industrial KURITZA (2012) e SWAMY et al. (2016) observaram comportamentos semelhantes ao utilizar o coagulante Cloreto de Polialuminio (PAC), sendo que seus resultados demonstram remoções entre 99\%para turbidez, $93 \%-84 \%$ para cor aparente e $70 \%-45 \%$ para DQO.

TAMOGAMI et al. (2014) realizaram processos de coagulação com o tanino em outro tipo de efluente industrial, também, com alta carga de matéria orgânica. Os resultados obtidos apontaram 95\%, 98\% e 63\% para turbidez, cor aparente e DQO.Sendo assim pode-se perceber que os estudos indicam a dificuldade 
encontrada para remoção de DQO. Atrelado à importância desse parâmetro no lançamento de efluentes em corpos receptores, indica-se um tratamento posterior por processos biológicos objetivando o alcance de melhores eficiências de remoção, sobretudo no que se refere a matéria orgânica.

\section{CONCLUSÃO}

De acordo com os testes realizados para avaliar a eficiência do tanino vegetal no tratamento por coagulação do efluente de uma indústria de papel, podese concluir, através da dosagem ótima obtida, de $125 \mathrm{mg} . \mathrm{L}^{-1}$, os valores de porcentagem de redução dos parâmetros avaliados alcançaram boas remoção no que se diz respeito à turbidez (88\%) e cor aparente (83\%).

Ainda que o tratamento baseado na coagulação/floculação/sedimentação não tenha alcançado valores elevados, este auxiliará para que as unidades posteriores tenham melhores condições operacionais com menores exigências de área.

\section{REFERÊNCIAS}

APHA - AMERICAN PUBLIC HEATH ASSOCIATION. Standard methods for the examination of water and wastewater. 22.ed. Washington: American Public Health Association. 2012.

AMARAL, M. C. S.; ANDRADE, H. L.; LANGE, C, L. Avaliação do emprego de microfiltração para remoção de fibras do efluente de branqueamento de polpa celulósica. Revista Engenharia Sanitária e Ambiental, v. 18, n. 1, p. 65-74. 2013. Disponível em: <http://dx.doi.org/10.1590/S1413-41522013000100008>

DI BERNARDO, L. Métodos e técnicas de tratamento de água. ABES, v.1, Rio de Janeiro. 1993.

DI BERNARDO, L.; DI BERNARDO, A.; CENTURIONE FILHO, P. L. Ensaios de Tratabilidade de Água E Dos Resíduos Gerados Em Estações de Tratamento De Água. São Carlos: Rima, 233 p. 2002.

GAVINO, W. R. G. Tratamento avançado de efluente de indústria de papel e celulose por processos de coagulação e ultrafiltração.2016.89 f. Dissertação (Mestrado) - Programa de Pós-Graduação em Engenharia Sanitária e Ambiental. Universidade Estadual de Ponta Grossa. Universidade Estadual do Centro-Oeste, Irati, 2016.

KURITZA, J. C. Aplicação da coagulação, floculação e sedimentação como póstratamento de efluente de uma indústria de papel e celulose. 2012. $127 \mathrm{f}$. Dissertação (Mestrado) - Curso de Pós-graduação em Ciências Florestais, Universidade Estadual do Centro-oeste, Irati, 2012.

MANCUSO, P. C. S.; SANTOS, F. Reúso da água. 3 ed. Barueri: Manuelie, 2003.

MARTIN, C. Indústria de celulose e papel registra contínuas reduções de consumo de água. O Papel, São Paulo, n. 19 p. 20-30, maio 2015. Mensal. Disponível em: < http://www.opapeldigital.org.br/pub/papel/?numero=19\&edicao=9038\#page/20>. 
MARTINS, A. A.; DE OLIVEIRA, R. M. S.; GUARDA, E. A. Potencial de uso de compostos orgânicos como, coagulantes, floculantes e adsorventes no tratamento de água e efluentes. Periódico Eletrônico Fórum Ambiental da Alta Paulista, v. 10, $\quad$ n. $12, \quad 2014 . \quad$ Disponível em: http://amigosdanatureza.org.br/publicacoes/index.php/forum_ambiental/article/view/9 13.

PELEGRINO, E. C. F. Emprego de coagulante à base de tanino em sistema de pós-tratamento de efluente de reator UASB por flotação. Dissertação de Mestrado. Programa de Pós Graduação em Hidráulica e Saneamento. Universidade de São Paulo, São Carlos, 2011.

SIMONIC, M; VNUTEC, D. Coagulation and UF treatment of pulp and paper mill wastewater in comparison. Central European Journal Of Chemistry, v. 10, n. 1, p.127-136, 24 nov. 2011. Walter de Gruyter GmbH. Disponível em: http://dx.doi.org/10.2478/s11532-011-0121-8.

SINGH, N. K.; PANDEY, S.; SINGH, S.; SINGH, S.; KAZMI, A. A. Post treatment of UASB effluent by using inorganic coagulants: Role of zeta potential and characterization of solid residue. Journal of Environmental Chemical Engineering, India, p. 1495-1503, 2016. Disponível em: $<$ http://dx.doi.org/10.1016/j.jece.2016.02.020>.

SRIDHAR, R.; SIVAKUMAR, V.; PRINCE IMMANUE, V, J.; PRAKASH MARAN, J. Treatment of pulp and paper industry bleaching effluent by electrocoagulant process. Journal of Hazardous Materials, v. 186, n. 2-3, p.1495-1502, fev. 2011. Disponível em: http://dx.doi.org/10.1016/j.jhazmat.2010.12.028.

SWAMY, N. K.; SINGH, P.; SARETHY, I. P. Effect of Sequential Treatment of Paper Industry Wastewater using Aluminum Chloride and Pseudomonas putida. Indian Journal Of Advances In Chemical Science, India, p. 226-229, 2016. Disponível em: <http://www.ijacskros.com/artcles/lJACS-2S-47.pdf>.

TAMOGAMI, C.; RIZK, M. C.; ALMEIDA, T. S. AVALIAÇÃO DO USO DE TANINO EM PH NEUTRO NO TRATAMENTO DE EFLUENTE DE CURTUME. $\mathbf{X}$ Fórum Ambiental da Alta Paulista, São Paulo, v. 10, n. 1, p.43-50, 2014. Disponível em:<http://www.amigosdanatureza.org.br/publicacoes/index.php/forum_ambiental/art icle/view/784/808>. DOI: 10.17271/19800827

THAKUR, S. S.; CHOUBEY, S. Use of Tannin based natural coagulants for water treatment: An alternative to inorganic chemicals. International Journal of ChemTech Research, v. 6, n. 3628, p. e3634, 2014. 